\title{
Developing an advocacy agenda for increasing access to opioid substitution therapy as part of comprehensive services for people who use drugs in South Africa
}

Opioid use disorders, including heroin use disorders, account for $70 \%$ of the global burden of drug-related disease ${ }^{[1]}$ and disproportionately affect people who have unmet social, emotional, economic, health and other needs. ${ }^{[2,3]}$ Heroin is widely available in South Africa $(\mathrm{SA})^{[4,5]}$ and there is an upward trend in numbers of people using heroin who access drug use treatment facilities registered with the South African Community Epidemiology Network on Drug Use. ${ }^{[6]}$ In addition, there is increasing concern around the link between injecting heroin use, hepatitis $\mathrm{C}$ virus (HCV) and HIV and the impact this could have on SA communities and the healthcare system. ${ }^{[7]}$

Opioid substitution therapy (OST), using an agonist or partial agonist, aims to alleviate the symptoms of opioid withdrawal, reduce cravings, and reduce the opioid response through receptor coverage. Over 40 years of research has shown that OST saves lives, ${ }^{[8-11]}$ improves retention in healthcare and treatment, ${ }^{[12-17]}$ reduces illicit heroin use, ${ }^{[12,13,17,18]}$ reduces interactions with the criminal justice system, ${ }^{[1,18,19]}$ reduces HIV risk ${ }^{[20-22]}$ and improves health and quality of life. ${ }^{[23-27]}$

Despite the increasing need and inclusion in the SA National Strategic Plan for HIV, TB and STIs $\left(2017\right.$ - 2021), ${ }^{[7]}$ none of the medications suitable for OST are listed on the Essential Drugs List (EDL) for maintenance prescribing. Methadone in SA is significantly more expensive than in other middle-income countries; for example, it costs up to 30 times more than the average cost in the Ukraine and Georgia. ${ }^{[28]}$ The high cost of methadone makes it unattainable for the majority of South Africans who need it.

The Sultan Bahu Centre in Cape Town was the first civil society organisation to provide OST, doing so for 3 months as part of an intensive outpatient offering. Since 2016, financed mainly by foreign donors, the Durban University of Technology, TB HIV Care and the Anova Health Institute have started providing OST to a small number of people who use heroin in Durban, Cape Town and Johannesburg. ${ }^{[29]}$ Since 2017, the City of Tshwane has funded OST as part of the community-orientated substance use programme run by the University of Pretoria. ${ }^{[31]}$ For the most part, however, people in SA who have a heroin use disorder view OST as an important service that is unaffordable and inaccessible. ${ }^{[30]}$

In view of the need for OST and growing local experience, we facilitated a half-day workshop at the 2017 South African Drug Policy Week to develop an advocacy agenda for OST in SA. Participants included academics $(n=6)$, OST prescribers $(n=3)$, co-ordinators from ongoing OST projects $(n=5)$, OST outreach staff $(n=6)$, and representatives from the Western Cape Government $(n=3)$, the pharmaceutical industry $(n=3)$ and the people who use drugs (PWUD) community $(n=2)$. Using the nominal group voting technique, research, policy, service delivery and collaborations were identified as OST advocacy priorities.

Research. Conducting research and economic evaluations on OST in SA's service delivery context, applying for funding, the publication of findings from local demonstration projects and documentation of changes in the quality of life of people on OST were seen as essential. Epidemiology and surveillance of opioid use disorders, the burden of illicit opioid use, and the possible impact of OST on the health sector and the economy were suggested as considerations for a future research agenda. Youth and women were also noted as important areas for research.
Policy. Inclusion of OST in the 2018 - 2022 National Drug Master Plan, inclusion of medications for OST (specifically methadone and buprenorphine/buprenorphine-naloxone) on the EDL for OST as maintenance at the primary care level, and decriminalisation of people who use substances listed as illicit in SA law (although the third item was unlikely to be achieved in the short term) were considered the main policy advocacy objectives.

Service delivery. Participants voted to prioritise the integration of OST into current civil society services as a move towards providing the World Health Organization's recommended package of services for people who inject drugs, inclusive of needle and syringe services, HIV and HCV prevention, testing and treatment services, and tuberculosis services, ${ }^{[31]}$ as well as management of minor wounds and common comorbidities, including non-communicable diseases, and access to voluntary psychosocial services. Ultimately these services, including OST, should become part of the public and private health service at all levels of care in urban and rural areas. The need for low-threshold services, paralegal support services and reduced costs was also discussed.

Collaborations and networks. Participants prioritised the establishment of a multisectoral OST advocacy group to lead advocacy efforts, the establishment of a website or Facebook page for sharing and accessing information, for publications and for networking, and the importance of the use of a common language for advocacy efforts. Funding was seen as critical to achieving these objectives. A mapping exercise identified other potential advocacy partners including clinician societies and associations, the South African National Council on Alcoholism and Drug Dependence, the Human Rights Commission, the various legal aid groups, and social movement organisations that mobilise around vulnerable groups. Unlikely partners such as the police, media, religious leaders and representatives from industry were viewed as vital actors in carving out an effective, sustained and recognised OST advocacy and implementation agenda.

The participants in the meeting identified a set of priority OST advocacy recommendations for SA:

- The National Drug Master Plan currently encourages harm reduction strategies as a means of caring for individuals already dependent on substances. The provision and support of OST by the National Department of Health $(\mathrm{NDoH})$ would solidify this commitment to harm reduction. It would also go a long way to improving the health and social outcomes and prognosis of people with opioid use disorders, their families and the broader communities affected by drug use.

- The NDoH should be encouraged to develop and implement policies and practice conventions that allow for the safe prescribing and dispensing of OST in the public health sector at all levels of care. OST outcomes are best when its implementation is regulated, monitored and easily accessible.

- Advocates need to engage with the NDoH Essential Drugs List Committee to incorporate OST medications as a form of maintenance treatment for use at the primary level of care.

- Researchers, service providers and other civil society organisations are encouraged to disseminate findings and lessons learnt related to OST interventions and research. The availability of local data 
will encourage and improve current debate and general awareness regarding OST in this country. The media are critical to achieving such public awareness.

- OST advocacy networks and organisations currently providing OST services should actively engage the public through open debate around the effectiveness of these medications.

- The costs associated with opioid substitution medications currently restrict availability to a small percentage of South Africans. Stakeholders (state and non-state) should work collectively to ensure that prices are reduced and that OST medication is made more affordable and accessible.

- OST advocacy efforts must be network based. Partners in these networks should include police, professional bodies, civic organisations, harm reduction service providers, PWUD and their communities. 'Whole of society' networks would have the capacity to reduce stigma and enable people who use heroin to access services.

Access to OST is a human right. People affected by opioid use disorders are marginalised and stigmatised, and it is critical that an advocacy network and agenda be established to give voice to this community. Further, we feel that it is important to map out a feasible way to roll out OST, an intervention that has been proven globally to be effective. While OST and other harm reduction programmes are currently only operational in the non-government sector, harm reduction is embedded (implicitly or explicitly) in key drug control and treatment legislation. It is time to align drug-related policies and to implement harm reduction interventions as promulgated in our existing progressive health-orientated legislation. Devising processes and institutional arrangements for making OST available in the public and private sector is essential if we wish to curtail what currently appears to be an emerging heroin use pandemic. Action is also required if we want to avoid the further marginalisation of an already excluded group of people.

Acknowledgements. Workshop participants: Shabir Banoo, Nelson Medeiros, Sibonelo Gumede, Chantelle Pepper, Lorinda Kroukamp, Ian Hove, Edward Sibanda, Bill Ebiti, David Jones, Anthony Manion, Lindi Shange, Siyasanga Ngcebetsha, Judith Schmidt, Vicky Turner, Nicky van der Walt, Zayne Joyne, Xolile Mayisela, Valmar Stuart, Freddy Nerinju, Kirsten Bobrow, Lusanda Rataemane, Sasha Lalla, Charlise Stander, Geraldine Wolmarans, Akrasi-Sarpong Yaw. Funders and partners of SA Drug Policy Week 2017: Open Society Foundations, TB HIV Care, Right to Care, Durban University of Technology, University of Pretoria, Bridging the Gaps through Mainline.

Author contributions. AS led the facilitation of the workshop, conducted the thematic analysis, drafted the initial version of the editorial and co-ordinated and consolidated co-author inputs. MM co-facilitated the workshop and revised and worked on elements of the editorial. SS participated in the planning of the workshop and provided inputs in the development of the editorial. TG participated in the workshop and provided inputs in the development of the editorial. AKD participated in the workshop and provided inputs in the development of the editorial. JH participated in the workshop and provided inputs in the development of the editorial.

Funding. Funders and partners of SA Drug Policy Week 2017: Open Society Foundations, TB HIV Care, Right to Care, Durban University of Technology, University of Pretoria, Bridging the Gaps and National Institute for the Humanities and Social Sciences.
Conflicts of interest. None. Methadone used in the OST demonstration project being conducted in Durban has been donated by Equity Pharmaceuticals.

\section{Andrew Scheibe}

TB HIV Care, Cape Town and Durban, South Africa; Department of Family Medicine, School of Medicine, Faculty of Health Sciences, University of Pretoria, South Africa; and Urban Futures Centre, Durban University of Technology, Durban, South Africa andrew.scheibe@gmail.com

\section{Monique Marks}

Urban Futures Centre, Durban University of Technology, Durban, South Africa

\section{Shaun Shelly}

TB HIV Care, Cape Town and Durban, South Africa; and Department of Family Medicine, School of Medicine, Faculty of Health Sciences, University of Pretoria, South Africa

\section{Tara Gerardy}

TB HIV Care, Cape Town and Durban, South Africa

\section{A K Domingo}

Department of Psychiatry, Faculty of Medicine and Health Sciences, Stellenbosch University, Cape Town, South Africa

\section{Jannie Hugo}

Department of Family Medicine, School of Medicine, Faculty of Health Sciences, University of Pretoria, South Africa

1. United Nations Office on Drugs and Crime. World Drug Report 2017: Executive Summary: Conclusions and Policy Implications. Vienna: UNODC, 2017. https://www.unodc.org/wdr2017/field/ Booklet_1_EXSUM.pdf (accessed 30 August 2018).

2. Scherbaum N, Specka M. Factors influencing the course of opiate addiction. Int J Methods Psychiatr Res 2008;17(Suppl 1):S39-S44. https://doi.org/10.1002/mpr.244

3. Price RK, Risk NK, Spitznagel EL. Remission from drug abuse over a 25 -year period: Patterns of remission and treatment use. Am J Public Health 2001;91(7):1107-1114.

4. Khine A, Mokwena K, Huma, Mempedi, Fernandes L. Identifying the composition of street drug Nyaope using two different mass spectrometer methods. Afr J Drug Alcohol Stud 2015;14(1). https:// www.ajol.info/index.php/ajdas/article/view/131003 (accessed 5 September 2018).

5. Weich L, Perkel C, van Zyl N, et al. South African Guidelines for the Management of Opioid Dependence. Johannesburg: South African Addiction Medicine Society, 2013.

6. South African Medical Research Council. South African Community Epidemiology Network on Drug Use. SACENDU reports 1998 - 2016. http://196.21.144.194/adarg/sacendu.htm (accessed 9 February 2018).

7. South African National AIDS Council. Let Our Actions Count: South African National Strategic 7. South African National AIDS Council. Let Our Actions Count: South African National Strategic
Plan for HIV, TB and STIs 2017 - 2022. Pretoria: SANAC, 2017. http://sanac.org.za/wp-content/ Plan for HIV, TB and STIs 2017 - 2022. Pretoria: SANAC, 2017. http://sa
uploads/2017/05/NSP_FullDocument_FINAL.pdf (accessed 30 August 2018).

8. Degenhardt L, Bucello C, Mathers B, et al. Mortality among regular or dependent users of heroin and other opioids: A systematic review and meta-analysis of cohort studies. Addiction 2011;106(1):32-51. https://doi.org/10.1111/j.1360-0443.2010.03140.x

9. Larney S, Toson B, Burns L, Dolan K. Opioid substitution treatment in prison and post-release: Effects on criminal recidivism and mortality. Monograph no. 37. Canberra: National Drug Law Enforcement Research Fund, 2011. http://www.ndlerf.govau/publications/monographs/monograph-37 (accessed 5 September 2018).

10. Fallis A. Determining the impact of opioid substitution therapy upon mortality and recidivism among prisoners: A 22 year data linkage study. Trends Issues Crime Crim Justice 2015;498(June):1-7. https:// aic.gov.au/publications/tandi/tandi498 (accessed 5 September 2018).

11. Mattick RP, Breen C, Kimber J, et al. Buprenorphine maintenance versus placebo or methadone maintenance for opioid dependence. Cochrane Database Syst Rev 2014, Issue 2. Art. No.: maintenance for opioid dependence. Cochrane Database

12. Veilleux JC, Colvin PI, Anderson J, York C, Heinz AJ. A review of opioid dependence treatment: Pharmacological and psychosocial interventions to treat opioid addiction. Clin Psychol Rev

2010;30(2):155-166. https://doi.org/10.1016/j.cpr.2009.10.006
3. Amato L, Minozzi S, Vecchi S, Davoli M, Perucci CA. An overview of Cochrane systematic reviews of pharmacological and psychosocial treatment of opioid dependence: Background paper for the meeting '1st Consultation on Technical Guidelines for Treatment of Opioid Dependence', Geneva, 1 - 4 November 2005. World Health Organization, November 2005. http://www.who.int/substance_abuse/ activities/overview_of_cochrane_systematic_reviews.pdf (accessed 30 August 2018).

14. Bell J, Zador D. A risk-benefit analysis of methadone maintenance treatment. Drug Saf 2000;22(3):179190. https://doi.org/10.2165/00002018-200022030-00002

15. Lingford-Hughes AR, Welch S, Peters L, Nutt DJ. BAP updated guidelines: Evidence-based guidelines for the pharmacological management of substance abuse, harmful use, addiction and comorbidity: Recommendations from BAP. J Psychopharmacol 2012;26(7):899-952. https://doi org/10.1177/0269881112444324

16. Van den Brink W. Evidence-based pharmacological treatment of substance use disorders and pathological gambling. Curr Drug Abuse Rev 2012;5(1):3-31. https://doi.org/10.2174/1874473711205010003

17. Dutra L, Stathopoulou G, Basden SL, Leyro TM, Powers MB, Otto MW. A meta-analytic review of puchosocial interventions for substance use disorders. Am J Psychiatry 2008;165(2):179-187. https://
psychen of psychosocial interventions for substance
doi.org/10.1176/appi.ajp.2007.06111851 
18. Connock M, Juarez-Garcia A, Jowett S, et al. Methadone and buprenorphine for the management of opioid dependence: A systematic review and economic evaluation. Health Technol Assess 2007;11(9):1171. https://www.ncbi.nlm.nih.gov/pubmedhealth/PMH0015139/ (accessed 5 September 2018).

19. Mattick RP, Kimber J, Breen C, Davoli M. Buprenorphine maintenance versus placebo or methadone Mattick RP, Kimber J, Breen C, Davoli M. Buprenorphine maintenance versus placebo or methadone
maintenance for opioid dependence. Cochrane Database Syst Rev 2014, Issue 2. Art. No.: CD002207. maintenance for opioid dependence. Cochrane Da
https://doi.org/10.1002/14651858.CD002207.pub4

20. United Nations Office on Drugs and Crime, World Health Organization, Joint United Nations United Nations Office on Drugs and Crime, World Health Organization, Joint United Nations
Programme on HIV/AIDS. WHO, UNODC, UNAIDS Technical Guide for Countries to Set Targets Programme on HIV/AIDS. WHO, UNODC, UNAIDS Technical Guide for Countries to Set Targets
for Universal Access to HIV Prevention, Treatment and Care for Injecting Drug Users - 2012 Revision. for Universal Access to HIV Prevention, Treatment and Care for Injecting Drug Users - 2012 Revision.
Geneva: WHO, 2012. http://www.who.int/hiv/pub/idu/targetsetting/en/ (accessed 30 August 2018).

21. Spire B, Lucas GM, Carrieri MP. Adherence to HIV treatment among IDUs and the role of opioid substitution treatment (OST). Int J Drug Policy 2007;18(4):262-270. https://doi.org/10.1016/j. drugpo.2006.12.01

22. World Health Organization, United Nations Office on Drugs and Crime, Joint United Nations Programme on HIV/AIDS. Substitution Maintenance Therapy in the Management of Opioid Dependence and HIV/AIDS Prevention. Position paper. Geneva: WHO, 2004. http://www.who.int/ substance_abuse/publications/en/PositionPaper_English.pdf (accessed 30 August 2018).

23. Strang J, Groshkova T, Uchtenhagen A, et al. Heroin on trial: Systematic review and meta-analysis of randomised trials of diamorphine-prescribing as treatment for refractory heroin addiction. Br J Psychiatry 2015;207(1):5-14. https://doi.org/10.1192/bjp.bp.114.149195

24. Van den Brink WW, Haasen C. Evidence-based treatment of opioid-dependent patients. Can J Psychiatry 2006;51(10):635-646. https://doi.org/10.1177/070674370605101003

25. Degenhardt $\mathrm{L}$ Larney $\mathrm{S}$, Gisev $\mathrm{N}$, et al. The impact of opioid substitution therapy on mortality postrelease from prison: Retrospective data linkage study. Addiction 2014;109(8)1306-1317. https://doi org/10.1177/07067437060510100310.1111/add.12536
26. Kourounis G, Richards BDW, Kyprianou E, Symeonidou E, Malliori M-M, Samartzis L. Opioid substitution therapy: Lowering the treatment thresholds. Drug Alcohol Depend 2016;161:1-8. https:// doi.org/10.1016/.drugalcdep.2015.12.021

27. Deering D, Horn J, Frampton CM. Clients' perceptions of opioid substitution treatment: An input to improving the quality of treatment. Int J Ment Health Nurs 2012;21(4):330-339. https://doi. org/10.1111/j.1447-0349.2011.00795.x

28. Management Sciences for Health, World Health Organization. International Drug Price Indicato Guide, 2014 edition. Medford: Management Sciences for Health, 2015. http://apps.who.int medicinedocs/documents/s21982en/s21982en.pdf (accessed 2 February 2018).

29. Right to Care. Prevention program for PWID. In: Country Portfolio Review. Pretoria: Right to Care, 2018

30. Shelly S, Broughton I, Mcbide A, et al. Every Single Person Looks At Us Bad. Cape Town: South African Network of People Who Use Drugs, 2017:1-43.

31. United Nations Office on Drugs and Crime, Joint United Nations Programme on HIV/AIDS, United Nations Population Fund, World Health Organization, United States Agency for International Development, US President's Emergency Plan for AIDS Relief. Implementing Comprehensive HIV and HCV Programmes with People Who Inject Drugs: Practical Guidance for Collaborative Inteventions. Vienna: UNODC, 2017. http://www.unaids.org/sites/default/files/media_asset/2017_HIV-HCVprogrammes-people-who-inject-drugs en.pdf (accessed 30 August 2018).

S Afr Med J 2018;108(10):800-802. DOI:10.7196/SAMJ.2018.v108i10.13397 